
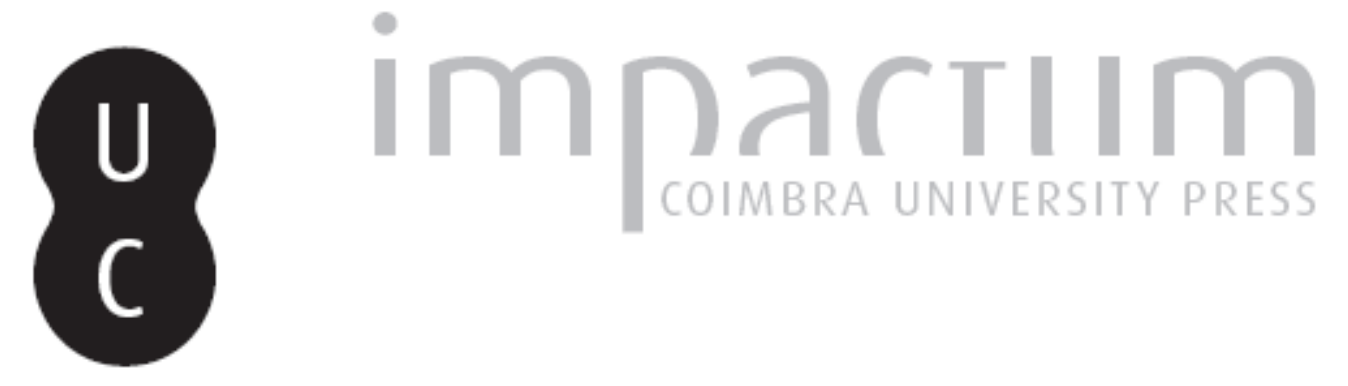

Os castelos e o conselho real: patrocínio político em Portugal (1495-1521)

Autor(es): $\quad$ Ferreira, Susannah Humble

Publicado por: Centro de História da Sociedade e da Cultura

URL persistente:

URI:http://hdl.handle.net/10316.2/39515

DOI:

DOI:http://dx.doi.org/10.14195/1645-2259_10-1_5

Accessed : $\quad$ 26-Apr-2023 15:07:03

A navegação consulta e descarregamento dos títulos inseridos nas Bibliotecas Digitais UC Digitalis, UC Pombalina e UC Impactum, pressupõem a aceitação plena e sem reservas dos Termos e Condições de Uso destas Bibliotecas Digitais, disponíveis em https://digitalis.uc.pt/pt-pt/termos.

Conforme exposto nos referidos Termos e Condições de Uso, o descarregamento de títulos de acesso restrito requer uma licença válida de autorização devendo o utilizador aceder ao(s) documento(s) a partir de um endereço de IP da instituição detentora da supramencionada licença.

Ao utilizador é apenas permitido o descarregamento para uso pessoal, pelo que o emprego do(s) título(s) descarregado(s) para outro fim, designadamente comercial, carece de autorização do respetivo autor ou editor da obra.

Na medida em que todas as obras da UC Digitalis se encontram protegidas pelo Código do Direito de Autor e Direitos Conexos e demais legislação aplicável, toda a cópia, parcial ou total, deste documento, nos casos em que é legalmente admitida, deverá conter ou fazer-se acompanhar por este aviso. 


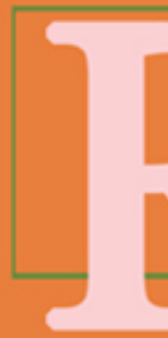

\section{evista de História}

da Sociedade e da

Cultura

\section{Tomo I}

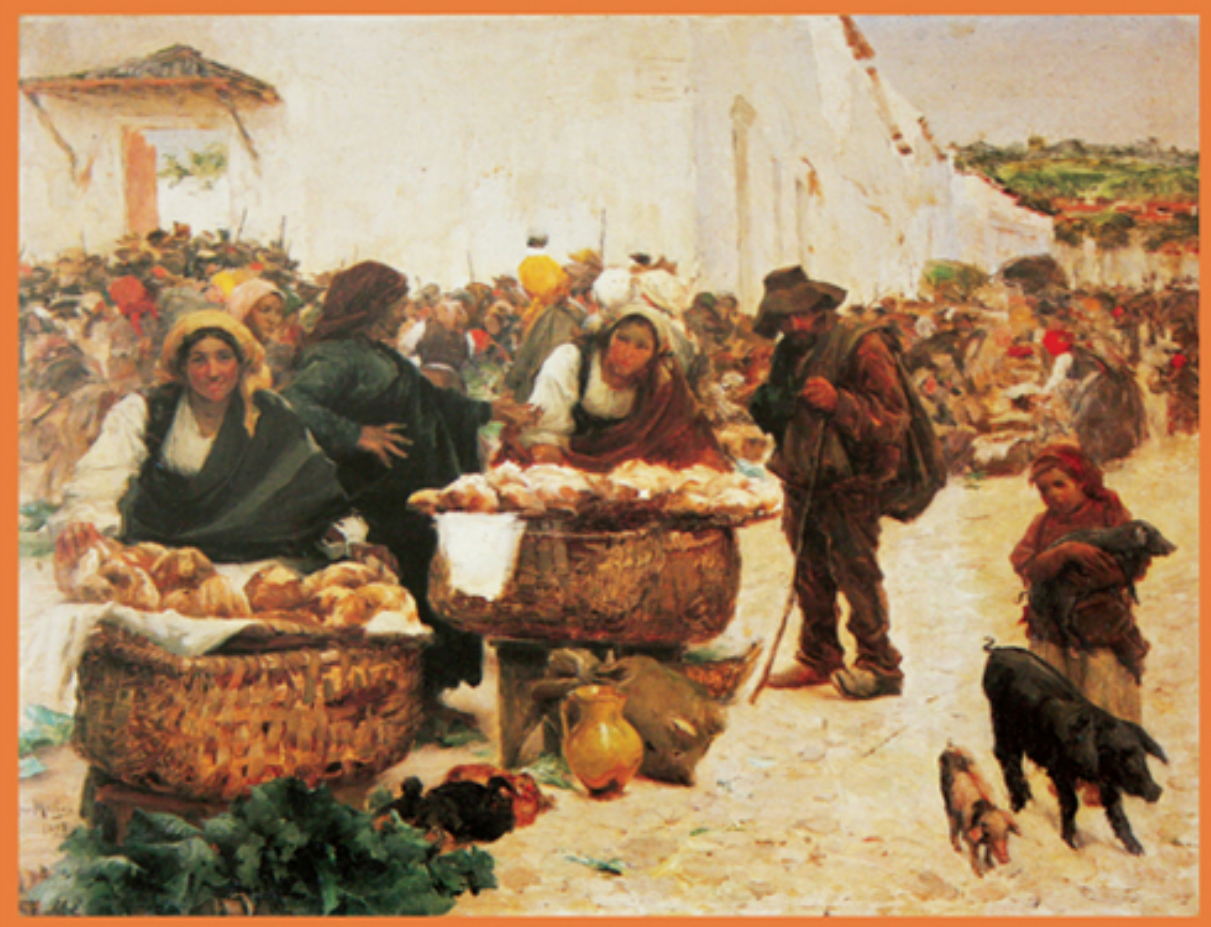

Centro de História da Sociedade e da Cultura Universidade de Coimbra

Coimbra 


\title{
Os Castelos e o Conselho Real: Patrocínio Político em Portugal (1495-1521)*
}

\author{
Susannah Humble Ferreira \\ University of Guelph, Canada \\ shumble@uoguelph.ca \\ Texto recebido em/ Text submitted on: 10/02/2010 \\ Texto aprovado em/ Text approved on: 19/04/2010
}

\section{Resumo/Abstract:}

No início do século XVI, um aumento de riqueza e de interesse em diplomacia resultou no crescimento da corte portuguesa, tanto em termos do número de pessoas como em termos espaciais (tamanho físico dos palácios). Este artigo tem como objectivo examinar os motivos por detrás da expansão do conselho real português durante o reinado de D. Manuel I (1495-1521) e postula que o rei terá empreendido essa expansão numa tentativa de criar laços verticais, ligando a corte com castelos situados na fronteira luso-castelhana. O conselho real operava como o núcleo político da nação e as posições no conselho conferiam prestígio, fazendo das nomeações para o concelho um importante veículo de patrocínio político. A motivação para expandir o tamanho do conselho do rei é contextualizada nas tensas relações entre Portugal e Aragão-Castela após a união das coroas em 1479.

At the turn of the sixteenth century, the Portuguese royal court grew both spatially and in terms of its personnel as a result of greater wealth and an increased interest in diplomacy. This paper examines motivations behind the expansion of the Portuguese royal council during the reign of D. Manuel I (1495-1521), and posits that the king undertook this expansion in an attempt to create vertical ties connecting the royal court to castles along the Luso-Castilian frontier. The royal council operated as the nucleus of the political nation and the positions on the council conferred prestige, making appointments to the council an important vehicle of political patronage. Motivation to expand the size of the king's council, is contextualized amid tense relations between Portugal and Aragon- Castile after the union of the crowns in 1479.

Palavras chave/Keywords:

Conselho Real; Alcaides Mores; D. Manuel I; Patrocínio político.

Royal Council; Alcaides Mores (chief magistrates); D. Manuel I; Political sponsorship.

* Agradeço a Ricardo Palma Ferreira por sua ajuda na tradução deste artigo de Inglês para Português. 
Em 1509, Duarte de Armas, escudeiro da casa real, cavalgou pelo reino de Portugal, ao longo da fronteira que partilhava com Castela. Armado com carvão e papel de linho, a missão do escudeiro era esboçar os castelos nas zonas fronteiriças portuguesas. Ele viria, mais tarde, a descrever os seus desenhos rudimentares no pergaminho Livro de Fortalezas, um tesouro nacional que, presentemente, se encontra na Torre do Tombo. A sua ilustração de sessenta castelos medievais, como se encontravam no início do século $\mathrm{XVI}$, completo com legendas detalhando vulnerabilidades estratégicas, defesas naturais, reparos urgentemente necessários, revela o intuito por detrás da sua missão: estudar a zona fronteiriça bem como o seu grau de preparação em caso de guerra. Nos desenhos originais, o escudeiro encarregou-se de listar os nomes dos alcaides que comandavam a fortaleza e a área à sua volta ${ }^{1}$. D. Manuel I (1495-1521) respondeu a deficiências estratégicas apontadas pelo seu escudeiro, não apenas ao mandar reparar estruturas danificadas, mas também ao forjar fortes laços verticais que ligavam tais castelos fronteiriços com a corte portuguesa.

O termo 'laços verticais', utilizado pelo historiador da França James Russell Major, refere-se às obrigações que ligavam senhores a vassalos e patronos a clientes. Assim como Major e outros, incluindo o historiador inglês K. B. MacFarlane, têm vindo a demonstrar, nas sociedades europeias medievais e no início da época moderna, tanto reis como nobreza governavam efectivamente através do cultivo e manipulação de laços verticais (por vezes referidos como afinidades políticas) ${ }^{2}$. A escassez de contratos formais e de listas detalhadas de aderentes associados com a coroa e nobreza portuguesas dificultam a pesquisa em comparação com o estudo de Inglaterra e França. A historiadora Rita Costa Gomes tem convincentemente vindo a demonstrar a relevância de tais laços na corte portuguesa nos

1 CASTELO BRANCO, Manuel da Silva (ed.) - Introdução in Livro das Fortalezas por Duarte de Armas. Lisboa: Edições Inapa, 1997, p. 1-16; GOMES, Rita Costa - A Castelos da Raia. Lisboa: IPAAR, 2002, p. xi.

2 MAJOR, James Russell - Representative Institutions in Renaissance France, 1442-1559. Madison: University of Wisconsin Press, 1960, p. 3-20; MCFARLANE, K. B. - The Nobility of Later Medieval England : the Ford Lectures for 1953 and Related Studies, eds. J. R. Highfield e G. L. Harriss. London: Oxford University Press, 1980. KETTERING, Sharon - Patrons, Brokers and Clients in Seventeenth-century France. New York: Oxford University Press, 1986. Mais recentemente, DUINDAM, Jeroen - Vienna and Versailles: The Courts of Europe's Dynastic Rivals, 1550-1780. Cambridge: Cambridge University Press, 2003. 
séculos XIV e $\mathrm{XV}^{3}$. A importância do patrocínio político na corte parece ter aumentado conjuntamente com o crescimento de recursos financeiros. Existem indícios de que tenças, que proliferaram durante o reinado de D. Manuel I, eram muitas vezes posteriormente redistribuídas por ele aos seus criados $^{4}$. A frequente menção de patrocínio político nos Ditos Portugueses, uma colecção de anedotas do século XVI, demonstra tanto uma expectativa de que os cortesãos seriam remunerados por quaisquer serviços prestados ao rei, assim como teriam poucas reservas em utilizar ligações ou solicitar recompensas à coroa 5 .

Embora as oportunidades apresentadas aos cortesãos fossem frequentemente concretas, as vantagens para a coroa em aumentar o tamanho da sua corte são mais difíceis de identificar. Roland Mousnier e subsequentes gerações de historiadores examinaram as ligações entre o surgimento do absolutismo e a atribuição ou venda de cargos públicos no século XVI ${ }^{6}$. Este artigo, não obstante, examina as nomeações de alcaides-mores para o conselho real como sendo uma estratégia através da qual D. Manuel I terá tentado solicitar o apoio em vez de subornar as suas elites com o intuito de obter uma maior influência real sobre castelos situados ao longo da fronteira luso-castelhana ${ }^{7}$. O seu objectivo é o de contextualizar o patrocínio político, a expansão da corte real e a dilatação do conselho, não somente como meras

3 GOMES, Rita Costa - The Making of a Court Society: Kings and Nobles in Late Medieval Portugal, trans. Alison Aiken. Cambridge: Cambridge University Press, 2003, p. 204-90. Ver também COSTA, João Paulo Oliveira e RODRIGUES, Vitor Luís Gaspar (eds.) - A Alta Nobreza e a Fundação do Estado da Índia. Lisboa: CHAM, 2004; COSTA, João Paulo Oliveira (ed.) - A Nobreza e a Expansão Estudos biográficos. Cascais: Patrimonia Historica, 2000.

4 Por exemplo uma tença de 30.000 réis a Luís de Meneses: Instituto Arquivos Nacionais/ Torre do Tombo (Lisboa), Chancelarias de D. Manuel, Livro 18, fl. 23.

5 Por exemplo dito $\mathrm{n}^{\circ}$. 15, SARAIVA, José Hermano (ed.) - Ditos Portuguesees dignos de Memóría: História intima do século XVI. Lisboa: Publicações Europa-America, 1997, p. 20.

6 MOUSNIER, Roland - La Vénalité des offices sous Henri IV et Louis XIII. Rouen: Editions Maugard, 1945. Estudos recentes atribuem maior agência de ofícios. Ver DESCIMON, Robert - Les élites du pouvoir et le prince: L'état comme enterprise in REINHARD, W.(ed) - Les elites du pouvoir et la construction de l'état en Europe. Paris: 1996, p. 133-162; ESTRELLA, António Jiménez - El Precio de las almenas: ventas de alcaidias de fortalezas reales en época de los Austrias. Revista de Historia Moderna: Anales de la Universidad de Alicante. 22 (2004), p. 7-74.

7 Para uma discussão completa dos papéis dos alcaides-mores ver MONTEIRO, João Gouveia - Os Castelos Portugueses dos finais da Idade Média. Coimbra: Edições Colibri, 1999, p. 235-312. 
projecções de riqueza e magnanimidade, mas como parte de uma política calculada de centralização de poder através de gastos sociais ${ }^{8}$.

D. Manuel I tem vindo a ser sido caracterizado, dentro da historiografia de Portugal, pelo seu epíteto "o Venturoso". Nascido em sexto lugar na linha de sucessão, chegou ao trono em 1495, após décadas de exploração portuguesa ao longo da costa africana e mesmo a tempo de colher os frutos da famosa viagem de Vasco da Gama à Índia. O seu reinado tem sido analisado pelas decisões políticas que afectavam o emergente império português ultramarino, conhecido como Estado da Índia. ${ }^{9}$ Embora reconhecido, o sucesso do rei na implementação de reformas extensivas (incluindo a reorganização do tesouro nacional, a compilação de código jurídico conhecido como as Ordenações Manuelinas, a padronização de pesos e medidas e a reforma de forais) é habitualmente apresentado como sendo menos importante que políticas falhadas respeitantes ao Estado da Índia.

Em termos de política social e relações entre a coroa e nobreza, a inflação do número de títulos hereditários durante o reinado de D. Manuel I contrasta com as restrições sobre privilégios da nobreza e o que é visto como um 'expurgo' da nobreza durante o reinado de João II, o seu predecessor (1481-1495). Em 1483, João II julgou e executou o poderoso duque de Bragança por traição. No ano seguinte, o duque de Viseu, irmão mais velho do futuro D. Manuel I e o maior magnata territorial, foi também ele executado por conspiração contra o rei. Rápidas represálias forçaram muitas outras elites políticas ao exílio em Castela. Quando D. Manuel I ascendeu ao trono era evidente que ele teria de empreender uma política de conciliação no que respeitava a nobreza; partilhando laços de parentesco e afiliações de serviço

8 Ver COSTA, João Paulo Oliveira - D. Manuel I. Lisboa: Circulo de Leitores, 2005, p. 100-101 para uma discussão sobre o patrocínio da nobreza e ampliação da corte por parte de D. Manuel I; também DIAS, João José Alves, BRAGA, Isabel M. R. Mendes Drumond e BRAGA, Paulo Drumond - A Conjuntura in DIAS, João José Alves (ed.) - Portugal do Renascimento à Crise Dinástica. Lisboa: Editorial Presença, 1998, p. 713-14.

9 Para os estudos biografias de D. Manuel I ver COSTA, João Paulo Oliveira e D. Manuel I e SANCEAU, Elaine - The Reign of the Fortunate King, 1495-1521. Hamden: Archon Books, 1970; também SUBRAHMANYAM, Sanjay - Career and Legend of Vasco da Gama. Cambridge: Cambridge University Press, 1997; THOMAZ, Luis Filipe - L'Idée Imperiale Manueline in AUBIN, Jean (ed.) - La Découverte, le Portugal et L'Europe, Paris: Calouste Gulbenkian, 1990; ALVES, Ana Maria - Iconologia do poder Real no Período Manuelino. Lisboa: Livros Horizonte,1985; AUBIN, Jean - Le Latin et L'Astrolabe. 
com muitos dos exilados, mas também necessitando do apoio e perícia do conselho e administração de D. João II. Seria, no entanto, errónea a visão de que o patrocínio de D. Manuel I evidencia que ele era manipulado pela nobreza, tal como seria enganoso ver as purgações de João II como uma indicação que ele seria mais independente e ‘moderno’ na sua visão política. Em ambos os casos, as circunstâncias políticas específicas e a disponibilidade de recursos ditaram o tratamento das elites políticas.

Tanto D. João II como D. Manuel I teriam tido conhecimento das vantagens que poderiam ser obtidas através do patrocínio político e gastos sociais, particularmente nos seus objectivos de cultivar laços verticais. Com esta finalidade, não havia nomeação mais valiosa do que uma nomeação para o conselho real. Para os aspirantes à elite política, uma nomeação para uma posição na casa real, com oportunidades de regalias politicas, remuneração associada e habituais gratificações, poderia ser mais valiosa que um título ou anuidade. De todos os cargos na corte, seriam os cargos de conselheiro ou cavaleiro do conselho, os mais atraentes para as elites políticas. Como uma manifestação institucional da filosofia da monarquia limitada, tão profundamente enraizada na cultura política portuguesa, o cargo simbolizava prestígio. O conselho continuou a operar como o núcleo político do reino quase até o final do século XVI, apesar do aumento do seu número de membros ao longo do tempo ${ }^{10}$. Mais ainda, os cavaleiros do conselho recebiam os mais altos níveis de remuneração na casa real e tinham direito a moradias, acima de 4.000 réis mensais, bem como roupas e outros privilégios ${ }^{11}$. No entanto, as frequentes queixas feitas em Cortes, nas quais a casa do rei representaria uma sobrecarga para os seus súbditos, levou a repetidas reduções no tamanho da casa real durante o século $\mathrm{XV}^{12}$. Por conseguinte, embora os possíveis benefícios possam ter

${ }^{10}$ Por os estudos sobre o conselho real ver BARROS, Henrique Gama - História da administração pública em Portugal nos séculos XII a XV, vol. 3. Lisboa: Livraria Sá da Costa, 1946, p. 251-60; CAETANO, Marcelo - História do Direito Português. Lisboa: Verbo, 1985, p. 481; HOMEM, Armando Luís Carvalho - Portugal nos finais da Idade Média. Lisboa: Livros Horizonte, 1990.

${ }^{11}$ Instituto Arquivos Nacionais/Torre do Tombo (Lisboa), Núcleo Antigo, no 924 e $\mathrm{n}^{\text {os }}$.835-859.

${ }^{12}$ SOUSA, Armindo - As Cortes Medievais Portuguesas, 1385-1490. Lisboa: Imprensa Nacional, 1990, p. 363, 384; DIAS, João José Alves (ed.) - Cortes Portugueses: Reinado de D. Manuel,( Cortes de 1498) Lisboa: CHAM, 2002, p. 179. 
vindo a ser reconhecidos, a carência económica e dependência financeira das Cortes contraíram o seu tamanho. Em 1402, o rei D. João I (1385-1433) que anteriormente apoiara um muito maior número de conselheiros, diminuiu o seu conselho para quatro membros ${ }^{13}$. As listas existentes de moradias compiladas por D. António Caetano de Sousa mostram que durante grande parte do século, o número de cavaleiros do conselho residentes na corte raramente excedia uma dezena ${ }^{14}$. Para mais, os regimentos contidos no Livro Vermelho do rei D. Afonso V (1438-81) reflectem as preocupações da corte sobre os encargos financeiros inerentes a uma grande casa ${ }^{15}$. Tais preocupações eram reais e evidenciadas pelo facto de que em 1510 a coroa estava ainda a pagar dívidas de casa real acumuladas trinta anos antes ${ }^{16}$.

Durante o reinado de D. Manuel I, o tamanho do conselho chegou a atingir cerca de 55 pessoas, sendo este o número de conselheiros residentes na corte aquando do terceiro casamento do monarca com Leonor de Áustria ${ }^{17}$. É inegável que a capacidade de D. Manuel I em suportar os custos de uma grande casa dependeu, em grande medida, da sua habilidade de colocar a casa real em bases financeiras mais sólidas. Mas a dilatação do conselho real, que parece ter ocorrido depois de 1510, coincidindo com a expansão em geral da casa real, não deverá ser vista como uma resposta automática ao repentino afluxo de riqueza comercial em Portugal. Pelo contrário, vínculos entre nomeações para o conselho real e o controlo de castelos fronteiriços vêem demonstrar os imperativos políticos que direccionaram a generosidade do rei durante a primeira década do século XVI.

O contexto das relações políticas entre Portugal e Castela serviu como pano de fundo para a eventual decisão por parte de D. Manuel I em recrutar

${ }^{13}$ DINIS, António Joaquim Dias (ed.) - Monumenta Henricina, vol. 1. Coimbra: Comissão Executiva do V Centenário da Morte do Infante D. Henrique, 1974, p. 280.

${ }^{14}$ SOUSA, D. António Caetano de - Provas de História Genealógica da Casa Real Portuguesa, vol. 3. Coimbra: Atlântida, 1947, p. 28-57, 217-24, 440-76.

${ }^{15}$ SERRA, José Correia de (ed.) - Livro Vermelho do Senhor Rey D. Affonso V, in Collecção de Livros Ineditos de História Portugueza dos reinados de D. João I, D. Duarte, D. Affonso V e D. João II, , vol. 3. Lisboa: Academia Real das Ciencias, 1793, p. 477.

${ }^{16}$ GOMES, Rita Costa - A Corte dos Reis de Portugal. Lisboa: Difel, 1995, p. 278.

${ }^{17}$ Instituto Arquivos Nacionais/Torre do Tombo (Lisboa), Núcleo Antigo, 140; cf. AUBIN, Jean - La noblesse titrée sous D. João III: Inflation ou fermeture in Le Latin et L'Astrolabe, cit., p. 371-83. FERREIRA, Susannah Humble - Development of the Portuguese Royal Council in the Reign of D. Manuel I (1495-1521). Portuguese Studies Review. 12 (2004), p. 1-17. 
alcaides para o conselho real. Portugal, após o tratado de Alcáçovas (1479), tem vindo a ser descrito por diversos historiadores como tendo embarcado numa política de neutralidade europeia, e tendo nos reinados de D. João II (1481-1495) e D. Manuel I (1495-1521), voltado a sua atenção para a fundação do seu império ultramarino ${ }^{18}$. Este retrato da diplomacia portuguesa durante o século XVI, embora correcto numa perspectiva a longo prazo, é demasiado simplista tendo em conta as pressões que o reino sofreu na Península Ibérica nos finais do século XVI. Excertos do Livro de Apontamentos de Álvaro Lopes de Chaves revelam que, no respeitante a Castela, a diplomacia portuguesa dificilmente pode ser considerada como monolítica e que a relação entre os dois reinos permaneceu tensa durante décadas depois da paz ter sido oficialmente declarada ${ }^{19}$.

A guerra travada com Castela (1475-9) por causa da sucessão de Isabel I viu Portugal decididamente derrotado e financeiramente prejudicado. Apesar disso, com a custódia de Joana, filha de Henrique IV (apelidada "la Beltraneja"), os portugueses mantiveram uma valiosa arma política. Embora de legitimidade questionável, a Excelente Senhora, como era conhecida em Portugal, seria uma alternativa a Isabel I, tanto dentro como fora de ambos os reinos. Embora os termos da paz negociados em 1479 a tenham confinado a um convento, ela continuava a ser uma potencial ameaça à segurança dinástica de Isabel I. Como tal, a paz que durou entre Portugal e Castela, no início da década de 1480 foi extremamente intranquila.

A crescente preocupação com o controlo de castelos fronteiriços, neste clima político, pode ser vista nas condições estabelecidas no importante acordo do tratado de Alcáçovas, conhecidas como Terçarias de Moura. Embora o aparente objectivo das Terçarias fosse o de garantir uma aliança dinástica com o noivado entre o príncipe Afonso de Portugal e a infanta

${ }^{18}$ MACEDO, Jorge Borges de e RAMOS, Luís Filipe - História diplomática portuguesa: constantes e linhas de força. Lisboa: Instituto da Defesa Nacional, 1987, p. 58-93; MARTINEZ, Pedro Soares - A Neutralidade Portuguesa desde o século XVI in Colóquio sobre Portugal e Paz. Lisboa: Academia das Ciências de Lisboa, 1989, p. 149-67; THOMAZ, Luís Filipe - O Projecto Imperial Joanino: tentativa de interpretação global de política ultramarino de D. João II in De Ceuta à Timor. Lisboa: DIFEL,1994, p. 149-67.

${ }^{19}$ CHAVES, Álvaro Lopes de - Livro de Apontamentos (1438-1489), ed. SALGADO, Anastásia Mestrinho e SALGADO, Abílio José. Lisboa: Imprensa Nacional, 1983, p. 254-255. Ver PINA - Crónica de D. João II, p. 62. 
de Castela, a custódia do jovem duque de Viseu por parte de Isabel I, ter-lhe-á teoricamente dado controlo sobre dezassete castelos portugueses pertencentes ao duque ${ }^{20}$. No entanto, aparentemente, João II terá contestado esta interpretação ao tentar alterar a forma dos juramentos através dos quais os seus senhores lhe prometeram lealdade. Na sessão inaugural das cortes, em 1481-1482, João II obrigou os seus vassalos a jurar que eles tinham os seus castelos e propriedades em "prestação" em vez de em juro e herdade, ou em perpetuidade. De acordo com esta modificação foi João II, e não Isabel I, que reivindicou autoridade sobre os castelos do ducado de Viseu, dando-lhe o direito de visitar e o direito de controlar a selecção de alcaides, que de outra forma the teriam sido negados ${ }^{21}$.

A selecção de alcaides-mores, cujas funções militares eram as de comandar os castelos e o controlo das áreas adjacentes, era uma questão crítica relacionada com a segurança do reino. A traição cometida pelo alcaide de Moura em 1478 comprometeu seriamente a posição de Portugal na guerra com Castela ${ }^{22}$. Mas a lealdade de alcaides não era fácil de obter, pois ao passo que a coroa manteve um direito teórico em manipular a sua selecção, na realidade, o ofício podia ser muito afastado do círculo de afinidades do rei. O peso das suas obrigações militares significava que, no século XIV, poucos alcaides encarregues de castelos fronteiriços conseguiram manter lugares na corte. Além disso, estes, que teoricamente eram não-hereditários, eram passados dentro de núcleos familiares de pai para filho, ou o parente masculino mais próximo, um facto que mais e mais os afastaram do controlo da coroa. Dadas as suas responsabilidades de recrutamento e abastecimento em tempos de emergência, os alcaides só podiam ser eficazes quando extraídos da nobreza ou de famílias que mantinham uma influência local significativa. Como o historiador Steven Ellis argumenta nos seus casos relacionados com a nobreza fronteiriça inglesa no início do século XVI, tais indivíduos e famílias tinham frequentemente as suas próprias lealdades e

${ }^{20}$ SUÁREZ FERNÁNDEZ, Luis. (ed) - Documentos referentes a las relaciones con Portugal durante el reinado de los reyes católicos, vol. 2. Valladolid: Consejo Superior de Investigaciones Científicas, 1958-63, p. 186-191.

${ }^{21}$ GOMES, Rita Costa - As Cortes de 1481-1482 in CURTO, Diogo Ramada (ed.) O Tempo de Vasco da Gama, Lisboa: DIFEL, 1998, p. 255-256.

${ }^{22}$ PINA, Rui de - Crónica de D. Afonso V in ALMEIDA, M. Lopes de (ed.) - Crónicas de Rui da Pina. Porto: Lello \& Irmão, 1977, p. 865-866. 
agendas políticas, que por vezes cruzavam fronteiras ${ }^{23}$. Foi ostensivamente, esta falta de controlo por parte da coroa que João II tentou reparar nas Cortes de 1481-1482.

A tentativa de João II em tentar assegurar o controlo sobre as alcaidarias por prerrogativa real não só contribuiu para o colapso do acordo das "Terçarias de Moura", que foi dissolvido nos finais da Primavera de 1483, mas contribuiu também para a agitação social dentro do reino. Os novos juramentos nas Cortes de 1481-1482, que efectivamente restringiram privilégios nobres, foram directamente responsáveis pela deteriorada relação entre o rei e o terceiro duque de Bragança e levaram, em última análise, à execução do duque em $1483^{24}$. As frágeis relações entre Portugal e Castela durante a década de 1480 foram marcadas pela tentativa de João II em 1482 (e de novo em 1485), de renovar a aliança militar entre Portugal e Inglaterra, através do noivado de sua irmã com o recentemente enviuvado Ricardo III, e a fortificação, em 1488, de castelos fronteiriços ${ }^{25}$. Embora as tensões se tivessem apaziguado em 1489 com o eventual casamento do príncipe Afonso com a infanta Isabel, a morte inoportuna de Afonso em 1491 renovou as hostilidades ${ }^{26}$.

Apesar da sucessão de D. Manuel I em 1495 ter significantemente melhorado as relações entre Portugal e Castela, esta melhora, que se baseou em laços dinásticos e relações pessoais, era um pouco efémera. No final do século $\mathrm{XV}$, a diplomacia luso-castelhana tinha sido levada a cabo pela mãe do rei, a infanta D. Beatriz que era também sogra de João II e a tia materna de Isabel I. A morte de Isabel I em 1504, seguida da morte da infanta D. Beatriz em 1506, sinalizou a mudança fundamental do clima diplomático, e que tenha talvez evocado receios relativos às ambições peninsulares de Fernando $o$ Católico. Enquanto a luta entre o rei Fernando e Filipe da Áustria sobre a coroa castelhana proporcionou um certo grau de protecção, a morte de Filipe em 1506 levou à situação pela qual Fernando $o$ Católico se tornou o regente de Castela. Dois anos depois, Fernando

${ }^{23}$ ELLIS, Steven - Tudor Frontiers and Noble Power. Oxford: Oxford University Press, 1995.

${ }^{24}$ SOUSA - História Genealógica da Casa Real Portuguesa, vol. 5, p. 244-46.

${ }_{25}$ CHAVES - Livro de Apontamentos, p. 254-59. PINA - Crónica de D. João II, p. 945.

${ }^{26}$ AUBIN, Jean - João II devant sa succession in Le Latin et L'Astrolabe, cit., p. 49-82. 
o Católico encarregou um certo Fernando de Peñalosa de empreender uma vistoria dos castelos situados nas fronteiras com Castela; uma acção que indubitavelmente levou D. Manuel I a patrocinar a missão do seu próprio escudeiro da casa, Duarte de $\operatorname{Armas}^{27}$. Embora Portugal não estivesse destinado a sofrer o mesmo destino de Navarra, anexada em 1512, a sua prolongada independência não poderia ter sido prevista numa época em que Fernando, o Católico aparentava realizar grandes ambições continentais. E a visão oficial de neutralidade portuguesa nessa altura, colorida com a recusa de D. Manuel I em apoiar Fernando o Católico no seu conflito com Luís XII, foi influenciada pela possibilidade de que o rei estaria, com um elevado grau de probabilidade, a apoiar discretamente a França ${ }^{28}$.

A preocupação com a segurança da fronteira poderá ter sido um factor importante em instigar D. Manuel I a aumentar o controlo real sobre os castelos na zona, através do cultivo de laços verticais. Em vez de assegurar o controlo directo sobre os castelos ou de interferir na escolha de alcaides, o rei parece ter-se valido do patrocínio político para cooptar o apoio das elites e nobres locais com influência nas zonas fronteiriças (e não só). Infelizmente, dada a escassa natureza de evidência documental, é difícil, ou quase impossível, determinar a maneira exacta como esta estratégia de selecção se desenrolou. O que se sabe é que o tamanho do conselho cresceu substancialmente durante o reinado de D. Manuel I. De acordo com o cronista Rui de Pina, João II terá tido conferências com um conselho de doze ${ }^{29}$. Ao passo que os primeiros anos de reinado viram um aumento inicial no conselho (atribuível à tentativa, por parte de D. Manuel I, de misturar os seus próprios apoiantes com os veteranos de D. João II), as trinta e oito nomeações formais de cavaleiro do conselho contidas nas chancelarias, datam todas de $1509 \mathrm{em}$ diante $^{30}$. Um fragmento de uma conta de vestiarias sugere que, por volta de

${ }^{27}$ GOMES, Rita Costa - A Ring of Castles: Fortresses of the Portuguese Frontier, vol. 1. Lisboa: IPAAR, 2002, p. XI.

${ }^{28}$ COSTA - D. Manuel I, p. 149.

${ }^{29}$ PINA, Rui de - Crónica de D. João II, p. 1028-29.

${ }^{30}$ Instituto Arquivos Nacionais/Torre do Tombo (Lisboa), Chancelarias de D. Manuel, Livro. 41 fl. 14v, 18, 20, 25, 27; Livro 3, fls.12, 20v, 27; Livro 7, fls. 4v, 8v, 48v, 10v,; Livro 37, fl. 64; Livro 15, fl. 189; Livro 11, fl.. 6, 72v; Livro 25, fls.. 16, 56v; 95v; Livro 10, fl. 68; Livro 9, fls. 16v; 46v; 61v; 57v; Livro 36, fl. $126,127 \mathrm{v}$; Livro 35, fls. 80; 83; 82; Livro 38, fl. 120v; Livro. 39, fls. 16v 106, 116; 112 113; 37; Livro 44, fl. 39v. 
1512, haveria perto de trinta cavaleiros do conselho a residir na corte, um número que em 1519 tinha crescido para cerca de cinquenta e cinco, um padrão de crescimento que aconteceu noutros locais na casa real ${ }^{31}$. Embora talvez pouco impressionantes em termos numéricos, as implicações relativas a este crescimento tornam-se visíveis pelo facto de que durante o reinado de D. Manuel I, pelo menos vinte cavaleiros do conselho eram alcaides de vinte e nove castelos, cuja maioria se encontrava nas comarcas estrategicamente vulneráveis da Beira e Alto Alentejo.

Com as nomeações de alcaides para o conselho real, D. Manuel I terá tido a expectativa de que estes homens vivessem na corte durante alguma parte do ano. Seria de esperar que os alcaides-mores de castelos importantes nomeassem alcaides pequenos para governarem as alcaidarias na sua ausência. Supunha-se que tais deputados fossem membros da família ou validos, possuíssem a influência e os conhecimentos necessários ao mesmo tempo que se mantinham ligados ao cargo seleccionado pela coroa através de laços sociais. Assim como o rei desenvolveu relações pessoais e exerceu influência sobre conselheiros na corte (e vice-versa), também estes controlavam e vigiavam as actividades dos seus deputados locais através de mensageiros e de visitas frequentes. Não teria sido do interesse de conselheiros reais desleixarem-se com posições sob o controlo deles, uma vez que o controlo de acontecimentos locais lhes proporcionava exercer a sua própria influência política. Desta forma nomeações plurais para o conselho e as alcaidarias fortaleciam os laços da coroa com os seus castelos, tanto na fronteira como em qualquer outra parte no reino.

É difícil generalizar quando se tenta descrever as maneiras pelas quais D. Manuel I procurou ligar as alcaidarias com cargos no conselho do rei. Em muitas instâncias, os homens que ocupavam os cargos de alcaide, e que tinham idade e estatuto social apropriados, eram nomeados cavaleiros do conselho. Nos primeiros anos de reinado, D. Manuel I aparenta ter seleccionado os seus conselheiros de entre o seu grupo de apoiantes e daqueles que mantinham forte influência local. D. Nuno Manuel e D. Diogo Silva e Meneses são bons exemplos. D. Nuno Manuel foi possivelmente

${ }^{31}$ Instituto Arquivos Nacionais/Torre do Tombo (Lisboa), Núcleo Antigo nos 924 e 140 e $n^{\text {os }} 835-59$. 
criado junto de D. Manuel I, uma vez que sua mãe, D. Justa Rodrigues Pereira, era a ama de D. Manuel I. Ele teria igualmente estado ligado com a casa ducal de D. Manuel I antes de 1495 tendo servido o duque como almotacé, cargo esse que manteve assim que D. Manuel I se tornou rei ${ }^{32}$. O pai de D. Nuno, o bispo da Guarda entre 1459 e 1475, extremamente influente naquela região a partir de 1465 , possuía direitos na cidade ${ }^{33}$. Aquando da ascensão ao trono de D. Manuel I, D. Nuno servia já como alcaide da Guarda. Embora não existam registos da sua nomeação, ele é mencionado como membro do conselho juntamente com o seu irmão D. João Manuel, no início do reinado de D. Manuel $\mathrm{I}^{34}$. O rei parece ter reforçado a influência de D. Nuno ao nomeá-lo senhor de Salvaterra de Magos em 1508 e permitindo-lhe adquirir as alcaidarias de S. Romão em 1507 e Idanha-a-Nova em $1508^{35}$. Existem poucas dúvidas de que D. Nuno era um candidato apropriado para ambas as tarefas. O seu pai tinha servido na corte como capelão-mor e conselheiro de Afonso V. Mais ainda, o facto de D. Nuno ter sido nomeado para o cargo de guarda-mor em 1515 mostra a sua capacidade de liderança militar ${ }^{36}$.

D. Diogo da Silva e Meneses foi o tutor de Manuel na sua juventude e acompanhou-o durante o breve período que residiu em Castela em 1481. Em 1495, D. Diogo tinha já as alcaidarias de três castelos: Almada, Assumar e Portalegre e pode até ter tido um cargo na corte de João II ${ }^{37}$. Não obstante, com a ascensão do rei, ele veio a ficar cada vez mais ligado à corte, servindo como escrivão da puridade, um cargo que automaticamente lhe conferiu um lugar no conselho. E, em 1498, o rei aumentou a sua influência, rendimentos e propriedades ao nomeá-lo conde de Portalegre. Como D. Nuno Manuel, D. Diogo tinha vindo de uma família extremamente influente na zona fronteiriça do Alto Alentejo, o seu pai tinha sido o alcaide de Campo Maior

${ }^{32}$ Instituto Arquivos Nacionais/Torre do Tombo (Lisboa), Chancelarias D. Manuel, Livro 30, fl. 21.

${ }^{33}$ FREIRE, Anselmo Braamcamp - Brasões da Sala de Sintra, vol. 3. Lisboa: Imprensa Nacional, 1973, p. 20-22.

${ }^{34}$ Ibid., p. 29.

${ }^{35}$ Ibid., p. 29; CASTELO BRANCO, intro. Livro das Fortalezas, 15.

${ }^{36}$ FREIRE, Anselmo Braamcamp - Brasões da Sala de Sintra, vol. 3, cit., p. 29.

${ }^{37}$ Ibid, p. 349; Instituto Arquivos Nacionais/Torre do Tombo (Lisboa), Leitura Nova, Misticos Livro 1, fl. 95; Instituto Arquivos Nacionais/Torre do Tombo (Lisboa), Chancelarias de D. Manuel, Livro 40, fl. 16v. 
e Ouguela durante os conflitos políticos da década de 1440. D. Diogo da Silva e Meneses era igualmente um homem com uma vasta experiência militar: tendo servido a coroa nas ilhas Canárias, Marrocos e Castela ${ }^{38}$. A nomeação de Lopo de Sousa, senhor de Paiva e Baltar, aparenta ter sido mais estratégica. Como tutor de D. Jaime, filho do terceiro duque de Bragança, Lopo de Sousa tinha mantido o seu cargo no exílio em 1483, regressando a Portugal em 1496. Em 1497, com o jovem duque de Bragança ainda um menor, Lopo de Sousa foi nomeado alcaide dos castelos de Bragança e Outeiro de Miranda em Trás-os-Montes. Embora a sua entrada no conselho não tenha sido registada nas chancelarias, ele parece ter sido nomeado antes de $1512^{39}$. As frequentes referências a Lopo de Sousa, na lírica poética da corte no início do século XVI, conhecida como Cancioneiro Geral, sugere que ele era bem conhecido na corte ${ }^{40}$. Como tal, Lopo de Sousa pode ser visto como representante de um laço valioso entre a corte real e o ducado de Bragança.

Uma outra estratégia levada a cabo pelo rei consistia em aumentar as bases do poder dos conselheiros de longa data em quem confiava, como D. Francisco Coutinho. Os seus objectivos, neste caso, parecem ter sido o equilíbrio do poder territorial dentro do reino e a criação de novas ligações com as regiões fronteiriças. D. Francisco Coutinho era um formidável candidato, pois vinha de uma família muito influente na região da Beira. Com a morte do seu irmão em 1471, ele herdou o título de conde de Marialva que lhe deu a posse das alcaidarias de Lamego, Penedono e Numão ${ }^{41}$. Em 1476, estes títulos aumentaram com as alcaidarias de Castelo Rodrigo e Castelo Bom ${ }^{42}$. Embora D. Francisco tivesse sido nomeado para o conselho durante o reinado de Afonso V, o seu nome encontra-se estranhamente ausente da lista de moradores em 1484, um detalhe que parece corresponder

${ }^{38}$ FREIRE, Anselmo Braamcamp - Brasões da Sala de Sintra, vol. 3, cit. p. 349-50.

${ }^{39}$ Instituto Arquivos Nacionais/Torre do Tombo (Lisboa), Núcleo Antigo, $n^{\circ} 924$.

${ }^{40}$ DIAS, Aida Fernanda (ed.) - A Temática in Cancioneiro Geral de Garcia Resende, vol. 5. Lisboa: Imprensa Nacional,1998, p. 224.

${ }^{41}$ FREIRE, Anselmo Braamcamp - Brasões da Sala de Sintra, vol. 1, cit., p. 59.

${ }^{42}$ CASTELO BRANCO - intro. Livro das Fortalezas, p. 15-16. Instituto Arquivos Nacionais/Torre do Tombo (Lisboa), Chancelarias de D. Manuel, Livro 20, fl. 15; FREIRE, Anselmo Braamcamp - Brasões da Sala de Sintra, vol. 3, cit., p. 310-311. 
com a diminuição do tratamento preferencial do rei $^{43}$. No reinado de D. Manuel I, ele é uma vez mais referido como membro do conselho e residente na corte em $1519^{44}$.

Em semelhança com o caso de D. Diogo da Silva, parece que D. Manuel I reforçou a influência local de D. Francisco ao autorizar o seu casamento com Dona Brites de Meneses, filha do primeiro conde de Loulé, em 1496. Tal gesto permitiu que D. Francisco, por meio da isenção da Lei Mental, herdasse novos títulos, jurisdições, terras no Sul do reino, bem como a alcaidaria de Loulé. Isto não só ligou mais um castelo à corte, como também forneceu a D. Francisco um contra-peso ao poder e influência dos duques de Bragança e Coimbra ${ }^{45}$. Posteriormente a única filha de D. Francisco, Dona Guiomar, ir-se-ia casar com o filho de D. Manuel I, o infante Dom Fernando, uma estratégia com o intuito de ligar ainda mais o património familiar com a coroa e a corte ${ }^{46}$.

Noutras situações, jovens bem posicionados para herdarem uma alcaidaria eram criados na corte como moços e cavaleiros fidalgos, antes de se tornarem cavaleiros do conselho uma vez que atingissem os requeridos trinta anos de idade, como era exigido pelas Ordenações Afonsinas ${ }^{47}$. Um exemplo disso foi Henrique de Melo. A família Melo tinha, desde há muito, ligações com as importantes alcaidarias fronteiriças de Serpa, no Baixo Alentejo. O seu avô, João de Melo, tinha sido alcaide de Serpa de 1438 até vir a falecer em $1482^{48}$. Pertencendo ao ducado de Viseu, Serpa era um dos castelos que João II pretendia reivindicar para si e, como tal, foi apreendido pelo rei após a execução do duque de Viseu em 1484. Todavia, a alcaidaria regressou ao comando de Garcia, pai de Henrique de Melo, em 1486, a pedido da infanta Dona Beatriz que tinha direitos legais ao castelo, mas provavelmente porque

\footnotetext{
${ }^{43}$ SOUSA, D. António Caetano de - Provas, cit., p. 217-24; OLIVEIRA, Luís Filipe - Outro Venturoso De Finais do Século XV: Francisco Coutinho Conde de Marialva e de Loulé, in A Alta Nobreza, p. 52.

${ }^{44}$ Instituto Arquivos Nacionais/Torre do Tombo (Lisboa), Núcleo Antigo, $n^{\circ} 139$.

${ }^{45}$ FREIRE, Anselmo Braamcamp - Brasões da Sala de Sintra, vol 3, p. 347; Instituto Arquivos Nacionais/Torre do Tombo (Lisboa), Chancelarias de D. João III, Livro 39, fl. $118 \mathrm{v}$.

${ }^{46}$ OLIVEIRA, Luís Filipe - Outro Venturoso, cit., p. 54.

${ }^{47}$ COSTA, Mário Júlio Almeida de (ed.) - Ordenações Afonsinas, vol. 1. Lisboa: Calouste Gulbenkian, 1998, p. 345.

${ }^{48}$ FREIRE, Anselmo Braamcamp - Brasões da Sala de Sintra, vol 1, cit., p. 453.
} 
uma localização tão estrategicamente sensível necessitasse de ser governada por uma família com fortes laços locais. No reino de D. Manuel, Henrique de Melo está firmemente ligado à corte e é mencionado como um fidalgo da casa real em 1498. Após a morte de seu pai em 1510, tornou-se alcaide de Serpa, e foi depois nomeado cavaleiro do conselho, em $1521^{49}$.

Terão também existido outros homens no conselho que serviram tanto como alcaides como conselheiros, acerca dos quais sabemos muito menos. Exemplo disso foi Vasco Eanes de Corte-Real (irmão dos exploradores Gaspar e Miguel Corte-Real), que serviu D. Manuel I como vedor. Mencionado como alcaide de Tavira, na costa algarvia, no Livro de Linhagens do século XVI, Vasco Eanes de Corte-Real é referido como cavaleiro da casa real ainda em 1501, mas é mencionado como conselheiro em $1512^{50}$. O almirante António de Azevedo, igualmente referido como conselheiro em 1512, exerceu, desde 1506, o cargo de alcaide de Juromenha, um castelo situado na fronteira do Alto-Alentejo ${ }^{51}$. Por cada exemplo de funcionários da coroa com ambos os cargos de alcaide e cavaleiro do conselho, as circunstâncias eram determinadas pela idade no caso do conselho real, pela existência de vagas no caso de alcaidarias e pela sua própria influência (tanto a nível local como central) aquando da nomeação. Deverá ser sublinhado que, com cada alcaide nomeado para o conselho, D. Manuel I aumentava o seu controlo sobre as fronteiras luso-castelhanas bem como a sua influência sobre a totalidade do reino, castelo por castelo.

Resta dizer que a habilidade de D. Manuel I em aumentar o tamanho do conselho real, assim como o da corte em geral, dependia da sua aptidão, não só de gerar mais rendimentos, mas também de os desviar para os cofres da casa real. Um dos maiores problemas que os tesoureiros da casa tinham de enfrentar, no final da Idade Média, vinha da prática corrente de pré-atribuir rendimentos da coroa, pelo que o dinheiro era pago localmente antes de chegar aos cofres centrais. Com este sistema, em que os rendimentos da

${ }^{49}$ Ibid , p. 455; Instituto Arquivos Nacionais/Torre do Tombo (Lisboa), Chancelarias de D. Manuel, Livro 39, fl. 106.

${ }^{50}$ FARIA, António Machado de (ed.). - Livro de Linhagens . Lisboa: Academia Portuguesa de História, 1956, p. 170; Instituto Arquivos Nacionais/Torre do Tombo (Lisboa), Núcleo Antigo no. 924.

${ }^{51}$ CASTELO BRANCO - intro. Livro das Fortalezas, cit. p. 15. 
coroa eram distribuídos por conveniência e não por prioridades, muito pouco dinheiro chegava aos cofres da casa real. Quando as dívidas excediam os rendimentos, o que era frequente, funcionários, membros e credores da corte deixavam de ser remunerados, provocando queixas nas Cortes.

Embora D. Manuel I desfrutasse das vantagens de uma grande riqueza pessoal, se comparada com os seus antecessores, foram indubitavelmente os lucros do comércio ultramarino que a longo prazo permitiram a expansão do conselho e corte reais. Em 1519 mais de setenta por cento das moradias pagas provinham do comércio de especiarias ${ }^{52}$. O sucesso com o qual a coroa portuguesa, no final do século XVI, se viu capaz de explorar os rendimentos do Estado da Índia tem sido largamente tratado por historiadores da expansão portuguesa $^{53}$. Mas a capacidade da coroa em aproveitar tal riqueza, para a poder usar a fim de garantir os custos de uma maior casa de forma permanente, resultou de uma abrangente reconstrução da sua administração financeira. A necessidade em direccionar a riqueza para os cofres da casa parece ter sido a base da maioria das reformas de D. Manuel I, muitas em andamento antes que o impacto da riqueza proveniente da expansão fosse previsto. Uma das mais óbvias formas com que a casa real e a corte foram capazes de capitalizar os lucros ultramarinos proveio da construção, iniciada em 1502, do novo Palácio da Ribeira, localizado directamente por cima da Casa da Índia, a agência de cobranças de rendimentos ultramarinos. Esta localização não só facilitava a comunicação entre os tesoureiros da corte e os funcionários da Casa da Índia, como também canalizava os rendimentos directamente para o coração da corte. E nos finais do reinado, afigura-se que muitos conselheiros, fidalgos e funcionários terão sido pagos com artigos de luxo e outros bens vendáveis como pimenta, vindos directamente do armazém da Casa da Índia ${ }^{54}$.

A circulação de dinheiro e mercadorias para os cofres da casa foi facilitada em 1504 pela criação do cargo de provedor, que operava como ligação entre

${ }^{52}$ FREIRE, Anselmo Braamcamp - Cartas de quitação del Rei D. Manuel, Archivo Historico Portuguez., 2 (1904), 159.

${ }^{53}$ GODINHO, Vitorino Magalhães - Finanças públicas e estrutura do estado in SERRÃO, Joel (ed.) - Dicionário de História de Portugal, vol. 3. Lisboa: Livraria Figueirinhas, 1979, p. 32-33.

${ }^{54}$ FREIRE - Cartas de Quitação, vol. 2, cit., p. 159. 
a Casa dos Contos, e o contador da casa. Em 1514, a fusão dos tesouros nacionais e da casa com a fundação dos Contos da Casa e Reino, vieram oferecer aos oficiais da corte uma maior flexibilidade com as despesas da casa real, permitindo-lhes mais fácil acesso às receitas de funcionários da Casa da Índia e a cobradores locais ${ }^{55}$. Para além destas mudanças existiram ainda as reformas da Fazenda em 1516 que não só simplificaram e regularizaram a cobrança de alugueis e impostos habituais, como a dízima e a sisa, mas também colocaram certos departamentos como as aposentadorias da corte sob o controlo dos vedores ${ }^{56}$. Tais reformas, o seu relacionamento com a casa real e o facto de terem sido iniciadas no início do reinado, sugerem ainda que a expansão do conselho e casa reais não foram somente uma reacção natural à nova riqueza de Portugal, mas parte de uma abrangente estratégia de centralização do poder real.

Ao descrever a estratégia que em última análise terá ajudado D. Manuel I a centralizar o poder político não devemos, como acautela o historiador Jeroen Duindam, interpretar o empenho do rei como acções de um monarca astuto a manipular uma desafortunada nobreza ${ }^{57}$. O patrocínio político, juntamente com uma política geral de conciliação, permitiram um mútuo benefício aquando da angariação do apoio da nobreza. Os alcaides teriam visto, tanto a sua nomeação para o conselho como a oportunidade de governar as suas alcaidarias remotamente a partir da corte, como um exemplo do natural progresso e retribuição por serviços prestados. Mais ainda, os nobres aumentaram a sua influência local ao receberem remunerações reforçadas sob a forma de moradias e outros privilégios, assim como a possibilidade de praticarem patrocínio político eles próprios, através da selecção de representantes. A proximidade com o rei significava também que esses mesmos nobres e outras elites locais tinham mais oportunidades de exercer influência sobre a coroa e de tentar satisfazer interesses pessoais ou locais.

A estratégia com que D. Manuel I alargou as suas afinidades políticas, através de nomeações, foi levada a cabo na casa real e não apenas no

${ }^{55}$ RAU, Virginia - A Casa dos Contos. Coimbra: Faculdade de Letras, 1951, p. 27.

${ }^{56}$ Instituto Arquivos Nacionais/Torre do Tombo (Lisboa), Chancelarias de D. Manuel, Livro 12, fl. 57; liv 42, fl. $12 \mathrm{v}$.

${ }^{57}$ DUINDAM, Jeroen - Vienna and Versailles: The Courts of Europe's Dynastic Rivals, 1550-1780. Cambridge: Cambridge University Press, 2003, p. 7-14. 
conselho real. Alguns moços de estribaria foram nomeados tabeliães públicos em todo o reino, tal como muitos fidalgos da casa real foram nomeados procuradores. Como com os alcaides chamados para o conselho real, estas nomeações serviam ambos os interesses do funcionário e do rei. O resultado, intencional ou não, foi uma dramática expansão no tamanho da corte real portuguesa nos finais do século XVI - uma expansão que teve inegavelmente consequências respeitantes a alterações culturais, itinerários tradicionais e habituais modos de funcionamento. O intrínseco valor político de manter um volumoso conselho e corte teria sido reconhecido por reis e elites muito antes do século XVI. Terão, igualmente, compreendido o papel desempenhado por nomeações no cultivo de laços verticais. Mas uma dilatação do conselho e da corte era proibitivamente dispendiosa. Assentar a casa real em bases financeiras suficientemente sólidas para sustentar não só o aumento de recursos, mas também uma máquina administrativa necessariamente mais sofisticada, era uma estratégia inviável em muitos reinos até à geral recuperação económica do século XVI. O repentino enriquecimento de Portugal na primeira década do século XVI contribuiu indubitavelmente para o seu crescimento vertiginoso cerca de 1510.

Contudo, o que parece ter provocado o alargamento do conselho real em particular foi a formidável ameaça à soberania portuguesa por parte das coroas de Aragão e Castela em 1479, o que criou um autêntico super-poder. D. João II tinha reconhecido que demasiada autonomia local representava uma fraqueza e tentou, no início do seu reinado, reivindicar publicamente a autoridade sobre as alcaidarias. As suas acções, que aparentam ter enfraquecido privilégios da nobreza, tiveram a indesejada consequência de polarizar profundamente as elites políticas portuguesas, o que colocou ainda mais em causa a sua própria segurança. Por conseguinte quando, face a novas ameaças por Fernando II de Aragão, Duarte de Armas entregou o seu relatório sobre as vulnerabilidades estratégicas do reino, D. Manuel I optou pelo uso de patrocínio para ganhar controlo sobre os castelos ao longo da fronteira luso-castelhana. 
Fig. 1 - Mapa da distribuição dos Castelos, onde o Alcaide-Mor era um Cavaleiro do Conselho

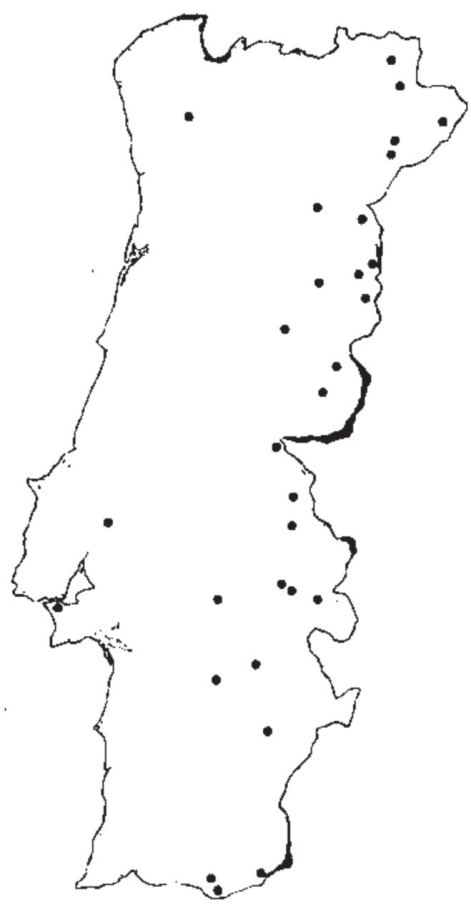

\section{CAVALEIROS DO CONSELHO}

Dom Diogo de Silva e Meneses

Dom Diogo Lobo

Dom Vasco Coutinho

Dom Francisco Coutinho

Dom Nuno Manuel

Dom Rodrigo de Castro

Dom Garcia Noronha

Dom Diogo de Meneses

Dom Pedro de Castro

Diogo Lopes de Lima

Garcia de Melo

Henrique de Melo

Lopo de Sousa

Henrique Correia

Vasco Eanes de Corte-Real

Rui Barreto

João de Faria

António de Azevedo

Álvaro Pires de Távora

\section{ALCAIDARIA}

ALMADA, ASSUMAR, PORTALEGRE

ALVITO

BORBA

MARIALVA C. BOM, C. RODRIGO, GUARDA, LOULÉ

IDANHA A NOVA, GUARDA

COVILHA

CARTAXO

MONTALVÃO

MONSANTO, CASTELO MENDO

GUIMARAES

SERPA

SERPA

BRAGANÇA, OUTEIRO DE MIRANDA,

VILAR MAIOR

TAVIRA

FARO

PORTEL

JUROMENHA

MOGADOURO, PENAS ROIAS, MIRANDA DO DOURO

Dom João Pereira, senhor de Castro Daire ARRAIOLOS 